\title{
The development of sexually dimorphic book-carrying behavior
}

\author{
THOMAS P. HANAWAY \\ Eastern State Psychiatric Hospital, 1509 Lyons View Drive, Knoxville, Tennessee 37919
}

and

GORDON M. BURGHARDT

University of Tennessee, Knoxville, Tennessee 37916

\begin{abstract}
We demonstrate that book-carrying behavior in grade school, junior high, high school, and college is sexually dimorphic. A book-carrying category system containing eight categories was employed to record the book-carrying styles of about 60 males and 60 females in each of 10 grade groups from kindergarten through college. Males and females employed similar carrying styles in kindergarten but differed significantly thereafter. The variety of styles employed diminished with age and sexual stereotypy increased. Males adopted adult-like carrying behavior at an earlier age than females, whose carrying styles showed little change between kindergarten and sixth grade, followed by a drastic change in junior high. Male-female differences in physical size, shape, and strength were considered in attempting to account for the sexually dimorphic carrying behavior. These variables, as well as others, are probably important in the development of book-carrying behavior but don't adequately account for the early appearance of sex differences.
\end{abstract}

Observational studies conducted during the past 4 years at the University of Tennessee establish that adult book-carrying behavior is sexually dimorphic. Most males carry books at their sides with their arms relatively straight while women usually rest the books on their hips or pelvic bones and cradle them with their arms (Hanaway, 1975; Jenni, 1975; Spottswood \& Burghardt, 1975). It appears that employing appropriate sex-typed book-carrying styles is important for peer acceptance. Students of high school age and older frequently describe, in pejorative terms, male peers that would employ a female book-carrying style. There appears to be more tolerance towards females than males that employ cross-sex-typed book-carrying styles (Hanaway, 1975). Book-carrying is an unexplored topic despite its ubiquity and the apparent social significance of employing appropriate carrying styles. The following study describes a methodology for investigating book-carrying behavior and some of the developmental aspects of book-carrying behavior.

\section{SUBJECTS AND SETTING}

Book-carrying styles were categorized for 589 males and 587 females ranging from kindergarten through college. There were 60-63 males and 60-63 females

This report is based on a dissertation submitted in partial fultillment of the requirements for the $\mathrm{PhD}$ degree at the University of Tennessee by the first author. The research was supported, in part. by Grant MH-15707 from the National Institute of Mental Health awarded to G.M.B. We thank the many persons who aided in this study. observed in each of the following grades or grade groups: first, second, third, fourth, fifth, sixth, junior high, senior high, and college. Thirty-eight males and 39 females were observed in kindergarten. The precollege students attended Knoxville, Tennessee public schools and lived in middle-class white neighborhoods. The mean house value, based on 1970 census data (Note 1), in the areas served by these schools was $\$ 27,000$. College students attended the University of Tennessee, Knoxville; a comparable economic statistic wasn't obtainable. The University of Tennessee student population is $95 \%$ white, and the other schools ranged from $99 \%$ to $100 \%$ white.

Students in kindergarten through sixth grade were observed as they carried books to or from the school library during their regular library class. Junior high through college students were observed as they were changing classes. Junior high and high school students were observed in hallways inside school buildings. A hallway was selected where, based on the advice of a schonl official, it was possible to observe a cross-section of the grades represented at the school. College students were observed at a number of sites on campus outside of classrooms.

\section{SUBJECT SELECTION}

When observing kindergarten and grade school students, the observer typically stood about $10 \mathrm{~m}$ down the hallway in the direction the students walked when returning to their classroom. An imaginary line was drawn across the hallway about 2 to $3 \mathrm{~m}$ from the library door. When the first student crossed this line, his 
book-carrying position was observed and recorded. The observer then observed the second student and recorded his position and so on with the other students. An attempt was made to record every book carrier in each class observed. This was sometimes impossible because: (1) students walked towards the observer faster than data could be recorded, (2) a student would be changing positions delaying recording of his position, or (3) an unusual position requiring a note slowed data recording. Accurate observation of each successive student became impossible because they were beginning to walk away from rather than towards the observer. When this occurred, the observer observed and recorded the subject directly in front of him. The next subject to be selected was whoever was directly in front of the observer when he looked up to make the next observation.

The following procedure was employed to select subjects in junior high, high school, and college because the density of students exceeded the observer's ability to observe and record data. Subjects were selected by walking through a designated space such as a doorway, one-half of a hallway, or the corner of an intersection. The size of this space was adjusted to facilitate efficient data recording. For example, at the beginning and end of the class change cycle in junior high and high schools, there were few students in the hallway, which allowed observation of every student. When this became impossible due to increasing traffic, the size of the space designating subjects was reduced. For example, only students on one side of the hallway were selected as subjects. As traffic continued to increase, the size of the space designating subjects was further reduced. When traffic decreased towards the end of the class change period, the space designating subjects was enlarged to facilitate efficient data collection. The space designating subjects was usually restricted in two or three steps as traffic increased and enlarged a similar number of times as traffic decreased.

\section{SUBJECT EXCLUSION}

Men carrying briefcases were excluded from observation unless they carried books in the other hand. Women were excluded if carrying a purse or coat on a stack of books or if a purse was slung from the shoulder on the same side of the body used for carrying books. If a purse and books were on opposite sides of the body, the subject was included. Subjects were also excluded if they walked and read, tossed, and caught, or played with, books or if they engaged in animated conversation with arm waving or were standing in line.

\section{DATA RECORDING}

A checklist category system consisting of eight book-carrying categories, designated as $\mathrm{A}$ through $\mathrm{H}$,
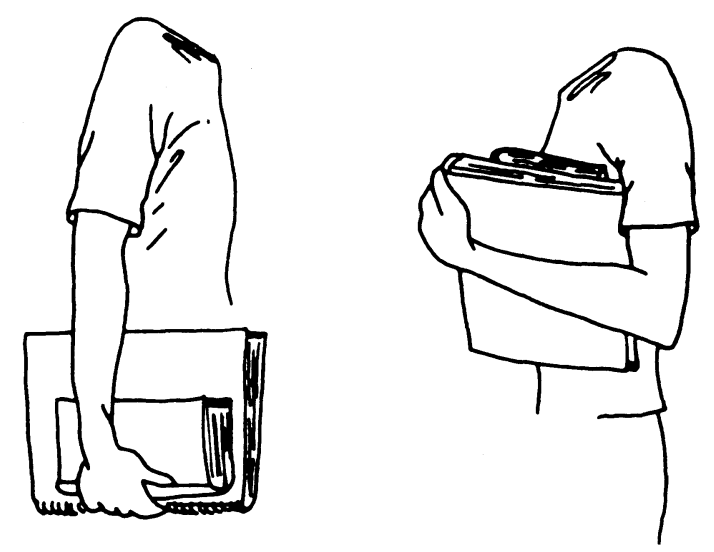

Figure 1. The two most common adult book-carrying positions. On the left is Position B, typically male, and on the right is Position G, typically female.

was used to record book-carrying behavior. The two most common categories for adults, Category B for men and $G$ for the women, are depicted in Figure 1. In Position A, the book is held between the hand and the ground and secured by the hand gripping the book with the fingers pointing downward. In Position B, the arm is relatively straight with the hand cupped under the lower edge of the book (Figure 1). Position C is similar to Position B but the arm is noticeably bent and the hand is somewhere between the waist and the location reached when the arm is straight. Position. $D$ is similar to $C$ but the arm is bent more and the hand is at the waist. The defining characteristic of Position $E$ is that the bottom edge of the book is held at a 45-deg angle to the ground, and the book is positioned at the front side of the book carrier. The subject's arm is noticeably bent and the hand is forward from the extreme side of the body. In Position F, the book rests on the subject's hip at the extreme side of the body and is cradled in the subject's arm. In Position G, the book is cradled in the arm, is held at the front side of the body, and rests on the hip or pelvic bone (Figure 1). In Position $\mathrm{H}$, the book is held with both hands or arms at the midline in front of the body. The book can be held nearly flat against the chest, parallel with the ground and serving as a tray for other books, or held by the hands while resting against the thighs, pubic area, or abdomen. Either one or two hands can be used in Positions B through $G$ although one hand is commonly used in Positions B through E. A student not using Positions A through $\mathrm{H}$ had his book-carrying position noted at the bottom of the data sheet. Occasionally subjects were changing positions when first observed. When this happened, they were observed until they completed the position change and were recorded as using the new position.

\section{RELIABILITY}

Reliability checks were conducted at two junior high schools, the University of Tennessee, and at a Knoxville public library where a sample of elementary 

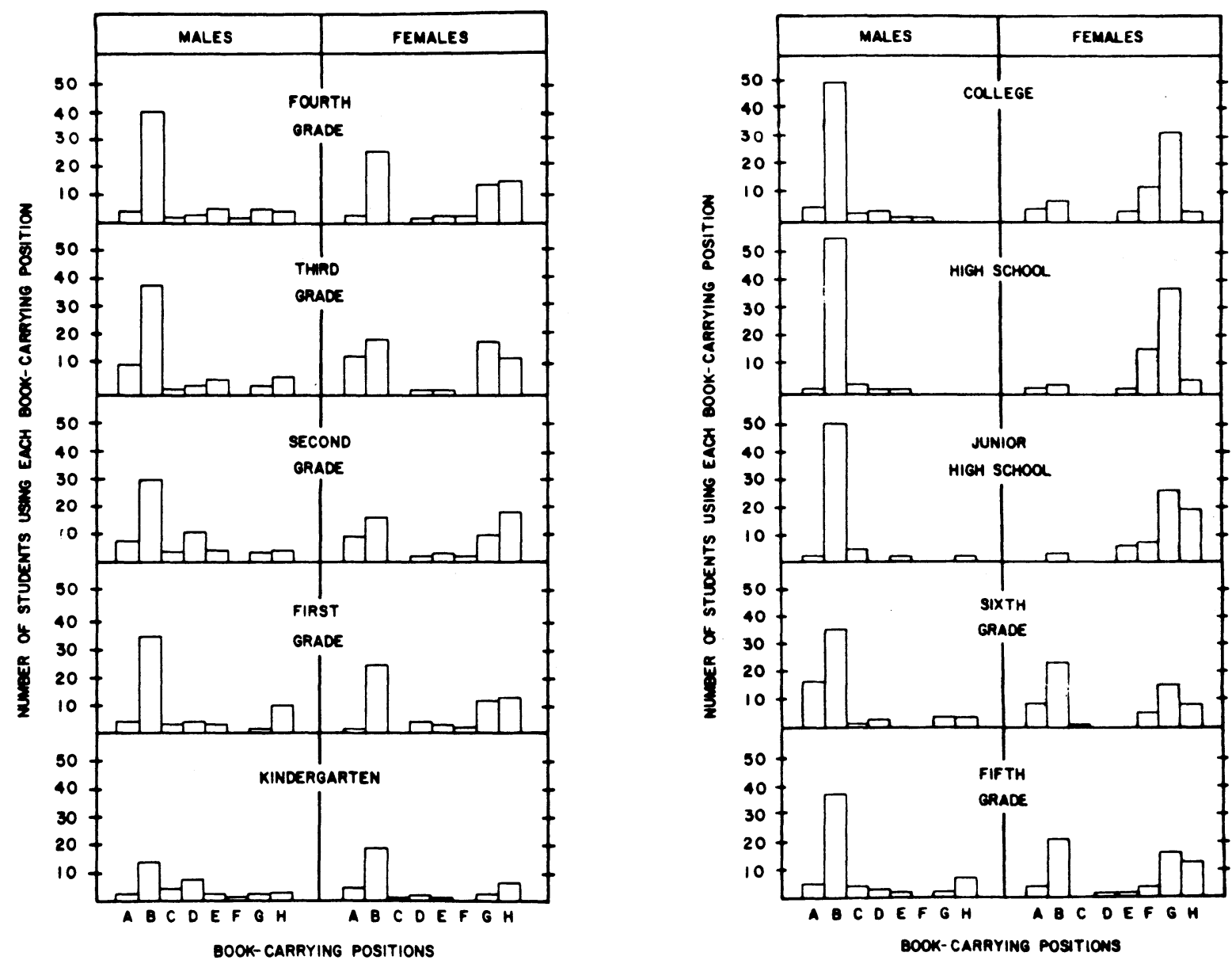

Figure 2. Book-carrying positions used by males and females in grades kindergarten through college.

school children was observed. There were 133 males and 128 females in the sample. The percentage agreement by position was: A, 88; B, 95; F, 81; G, 75; and $H, 91$. Percentage agreement is only given for positions used more than seven times in the reliability sample. The percentage agreement for combined Position $F$ and $G$ and $H$ was 96. Percentage agreement was computed by dividing the number of agreements by the sum of agreements plus disagreements times 100. Except for junior high students, the data reported above was collected solely for purposes of checking reliability and isn't included in the study.

\section{RESULTS}

Figure 2 depicts the book-carrying methods used by the male and female students from kindergarten through college. Eighteen of 1,176 students used Position "Other." Because of its infrequent occurrence, it isn't included in Figure 2. The data were analyzed for sex differences by grade using chi-square tests of significance. In order to minimize the number of cells having expected values less than five (Siegel, 1956), the number of book-carrying categories was reduced from eight to five by combining categories with similar topography. Two new categories were made by combining Categories B, $\mathrm{C}$, and $\mathrm{D}$ and Categories $\mathrm{F}$ and $\mathrm{G}$.

Except for kindergarten students, the bookcarrying categories employed by males and females differed significantly $(\mathrm{p}<.05$ for first grade males and females and $p<.001$ for all grades thereafter). Males show an increase in the use of Position B from kindergarten through college (Figure 2). In the early grades, male carrying behavior shows considerable variability. As the use of Position B increases, Positions $\mathrm{F}$ through $\mathrm{H}$ are used less frequently, rarely being used after sixth grade. In contrast with the gradual changes observed in males, female book-carrying behavior changes little until after sixth grade. Until sixth grade, females are as likely to use Positions A and B as F, G, and H. After sixth grade, Positions $F, G$, and $H$ become the predominant female book-carrying position.

\section{DISCUSSION}

Male-female differences in size, strength, and body shape are three variables that might be considered to account for sex-related book-carrying differences. However, growth in height and weight 
are quite similar for males and females until about age 14, when males, who are slightly behind due to females beginning puberty earlier, catch up and surpass females (Krogman, 1972). The sexually similar growth patterns are in contrast to the sexually dimorphic book-carrying methods. It is assumed that the development of fingers and arms parallels overall height and weight development prior to adolescence. According to Methany (1941), male and female grip strength develops linearly from age 6 to 12 , with males exceeding females by about $2 \mathrm{lbs}(1 \mathrm{~kg})$ at each grade. Jones (1949) tested grip strength, arm pull, and arm thrust on children aged 11 to 17. Except for arm thrust, prepubertal males were stronger than females. But strength differences diverged markedly after puberty. Although strength differences may influence book-carrying methods, a consistent explanatory relationship is absent. For example, stating that a male strength advantage accounts for gendered book-carrying behavior suggests a positive correlation between strength and the observed frequency of book-carrying Positions A and B. This is only true for males. Although both males and females get stronger with age, female use of book-carrying Positions A and B is relatively stable until sixth grade and then decreases markedly. If strength accounted for book-carrying differences, fourth grade girals might be expected to carry books like third-grade boys. Some do, but many don't, and the male-female differences are statistically significant in the early grades.

Male and female body-shape differences might be an important factor in adult carrying differences but, like size and strength, its importance prior to adolescence seems doubtful. No systematic body measurements were made, however the shape of early elementary males and females appears similar.

Although size, strength, and body shape seem to relate poorly to sexually dimorphic book-carrying differences, a marked change occurs in female book-carrying behavior that coincides with puberty. These physical variables may lack explanatory value prior to adolescence, but the data depicted in Figure 2 suggests that they cannot be considered irrelevant. Social factors may. of course. underlie the degree of stereotypy noted in post-elementary grades. As mentioned earlier, boys appear under more peer pressure to use only "masculine" methods than are girls for use of "feminine" methods. Our data shows much more stereotypy for males than for females.
For postpuberal males and females. the positions used may indeed be more comfortable due to physical differences in body and limb shapes. But why then do differences appear so much earlier? It could be that modeling of children upon older members of their sex does occur, and this leads them to adopt a carrying posture which will be adaptive for them at a later time. Such social processes may be more ubiquitous than may have been apparent in the past and question the exclusiveness of one function of play, that it is practice for later and more important behavior.

But the above is currently mere speculation. We need studies of a cross-cultural nature, particularly cultures without books, as well as observations on the carrying of objects other than books.

\section{REFERENCE NOTE}

1. Census Bureau. U. S. Department of Commerce, HC(3). Block Statistics. Knoxville. Tennessee, Report 219. 1971.

\section{REFERENCES}

Hanaway, T. P. The development of gendered book-carrying behavior. Unpublished doctoral dissertation, University of Tennessee, 1975.

JENNI. M. A. Sex differences in carrying behavior. University of Montana, Unpublished manuscript. 1975.

JONES. H. E. Motor performance and grow'th. Berkeley: University of California Press. 1949.

Krogman, W. M. Child growth. Ann Arbor: University of Michigan Press. 1972.

Methany, E. The present status of strength testing for children of elementary school and preschool age. Research Quarterly. 1941. 12. 115-130.

SIEGEL, S. Nonparametric statistics for the behavioral sciences. New York: McGraw-Hill, 1956.

SPOTTSWOOD. P., \& Burghardt, G. M. The effects of sex, book weight and grip strength on book-carrying styles. University of Tennessee. Unpublished manuscript, 1975.

(Received for publication November 10, 1975.) 